\title{
Identity Issues and Challenges Faced by Russian \\ Immigrants in New Zealand
}

\author{
Elena Maydell and Marc Wilson
}

\begin{abstract}
Among the processes cosmopolitan societies undergo at the present moment, is the unprecedented increase in mass migration across cultures. What challenges are faced by both immigrants, who have to settle in novel socio-cultural environments, and by the host populations accepting them? The current qualitative study investigates the nature of identity construction among Russian-speaking immigrants in New Zealand, applying thematic analysis for the interpretation of the data collected via 23 in-depth interviews. Among the most common themes articulated by the participants was the feeling of identity loss. A taken-for-granted sense of identity, brought by the participants from their culture of origin, was not validated by their new society of residence, mostly due to the lack of appropriate cultural resources. The participants were faced with a challenge of re-constructing their old identity, or constructing a new one, utilising the available resources in the community around them. At the same time, there was a sub-group for whom this challenge brought the realisation that the nature of their identity is cosmopolitan, rather than located within any particular culture or geographical space.
\end{abstract}

\section{Introduction}

The end of the previous century has witnessed significant changes in political and social life of different nations across the globe. As many theorists argue, humanity in the beginning of the $21^{\text {st }}$ century has found itself deeply entrenched in the powerful processes often summarized under the term 'globalization' (Scholte, 2005). Within these processes, characterized by new information technologies and increasing flows of goods, people and ideas, such new entities as 'global space’, 'global civil society' and 'global consciousness' pave the way to new approaches of understanding and reconstructing the concepts of self, identities and nationhood (Chandler, 2005). The constructionist argument, that individuals and society are co-created through multiple connections and discursive practices (Gergen, 1991), has been strengthened by new global discourses and current developments in various spheres of political and social life of people in many countries of the world, as the growing interconnectedness of numerous agents around the world erases distances and boundaries between them (Chandler, 2005).

Among recently emerged discourses, the concept of a global or transnational civil society is both the product and the producer of a new kind of morality and global 
consciousness, aimed at re-instating human agency outside of state-based politics. As power inequalities have pervaded not only national but also international relations, the political agenda of global civil society is to present 'an alternative moral force which can challenge and restrain the amoral world of international relations' (Chandler, 2005, p.111). Within this political project, global civil society seeks to articulate universal values and global issues in contrast to the particular state-based interests, bringing to the discussion table the issues of 'global space' and 'global consciousness' (Chandler, 2005).

The idea of a new kind of 'social space' as a manifestation of globality, as a nonterritorial or sub-territorial concept, transcending borders and geographical locations, may be defined through ideological frames and global values (Scholte, 2005). Current developments in new information technology create a simultaneous interconnectedness between people around the world and can make 'local' events global in an instant, radically transforming 'people's consciousness from the national to the global level' (Chandler, 2005, p. 115). Shaw (2000) suggests that this new, 'global', consciousness is based on new social meanings created by the transformation in the concepts of time and space and it entails 'an increasing awareness of the totality of human social relations' (pp.11-12).

As the processes of globalization sustain the growing complexity of human experience, the idea of a global civil society reflects the increasing global interconnectedness and promotes 'a culture of self-awareness about the hybridity and complexity of the world' (Keane, 2003, pp. 15-16). This new concept of 'globally aware' people, who present the force behind global civil society and spread the new global consciousness, building up resources for new social meanings, constructs the basis for the re-articulation of human agency on a global level.

Thus, new global space create new actors, who, in turn, further develop the complexity and diversity of manifestation of these global meanings. For Chandler (2005), this new social space is 'the most inclusive, a space which is shared by every diverse identity' (p. 117). The process of co-construction between these global actors and global space allows for the emergence of new meanings for such concepts as identity, nationhood and human rights. 
As a result of globalization and decline of nation-states' influence, the issue of human rights has outgrown the boundaries of states and reached the global or cosmopolitan level (Chandler, 2005). Therefore, the democracy has to be extended from nationstates to humanity as a whole, as in contrast to the rights of states, it should be the rights of cosmopolitan or global citizens, which can be addressed through global civil society. In this regard, more and more citizens of nation-states demand the rights of global or cosmopolitan citizenship, extended beyond the state boundaries (Chandler, 2005).

Among these global citizens there are numerous immigrants and refugees crossing national borders who represent the new global actors with cosmopolitan demands. As Nash, Wong and Trlin (2006) state, 'The movement of people (voluntary and forced) across borders is an international phenomenon, an expression of globalization with implications for national, economic and political stability and cultural identity’ (p. 346).

The end of the last century and the beginning of this one have witnessed the unprecedented and continuous increase in both voluntary and involuntary mass migrations from different regions of the world, reflected in such metaphors as 'waves' or 'flows' (Markowitz, 2004). The changes have occurred not only in numbers and origins of people moving across the globe; the nature of immigration has changed dramatically, making a huge impact on the whole global community (Suarez-Orozco, 2005).

As one of the impacts of increased migration, new ways of identity production become salient not only for immigrants themselves, but also for the members of host communities affected by the exposure to different cultures and new worldviews (Castles \& Miller, 2003). Resnik (2006) suggests that local communities cannot ignore the effects of the global processes of identity production which are introduced by immigrants in their struggle for acknowledgement and social inclusion. She states that, 'One of the main characteristics of our time is the instability of identities and the continuous invention of new/old identities. Traditions and ethnic identities are 
deconstructed and reconstructed. Immigrants... participate in the dynamic of identity production’ (Resnik, 2006, p. 585).

The concept of identity, as understood within this research, is adopted from the constructionist perspective (Burr, 1995). Gergen (1991) suggests that a person’s identity is constructed in discursive practices, specifically through continuous interactions and relationships with others, as well as with the immediate environment. This particular environment includes not only the people and community around, but also spatial and historic characteristics a person finds herself in. People reflect the histories of their culture(s), enacting them through their identities, and carry their cultural flags and symbols, passed to them by their predecessors, which they pass on later to their successors (Liu \& Hilton, 2005; Liu, McCreanor, McIntosh \& Teaiwa, 2005).

In this regard, identity may be conceptualised as a flexible and unstable concept which undergoes continuous deconstruction and reconstruction (Resnik, 2006). This becomes very clear in the case of immigrants who learn about how unstable their identities are through personal and direct experiences, as a result of leaving their habitual cultural environment, which provided them with the validation for their sense of being, and through losing this sense in new lands.

The new cultural systems of meanings usually lack the same resources which immigrants relied on in their homeland as material for identity construction (MaydellStevens, Masgoret \& Ward, 2007). Sampson (1989) argues that the ownership over socio-cultural resources, essential for identity construction, lies with the community, which accumulates and continuously re-produces these resources. Consequently, immigrants have to go through a learning process of familiarizing themselves with the local socio-cultural environment, in order to be able to construct or re-construct their identities, re-claiming their ownership over the available resources (Rapoport, Lomsky-Feder \& Heider, 2002).

The current research is focused on the process of identity construction among Russian-speaking immigrants who have been in their new country of residence, New Zealand, for less than 10 years, on the assumption that they are still in the stage of the 
active re-construction of their identity. The participants in the study were recruited in Wellington and its suburbs.

The Russian-speaking community in New Zealand may be considered a small cultural group, as there have never been any large-scale migrations of them to New Zealand. In contrast, countries such as the USA, Canada, Israel and some others have received large numbers of Russians and other ethnicities from territories of the former Soviet Union, triggering academic interest in such topics as identity production (e.g., Elias, 2005; Rapoport et al., 2002; Resnik, 2006; Vinokurov, Birman \& Trickett, 2000).

The 1996 Census data show that approximately 3,000 New Zealand residents stated Russia as their birth place, while 5,600 people were identified as being able to speak the Russian language (9\% exclusively; Statistics New Zealand, 2002). Though not all would state their ethnicity as Russian (but rather as Ukrainian, Kazakh, Jewish, and others), their main language would be Russian. This can be explained by the legacy of the Soviet Union, whose policies aggressively promoted forceful Russification of ethnic minorities, and insisting on the supremacy of the Russian language and Russian culture among its citizens (Kononenko \& Holowinsky, 2001).

Despite these statistical data, Russian-speaking immigrants in New Zealand are considered one of the groups whose numbers are rising faster than others. The Report on migration trends for the 2005/2006 financial year cited 1,003 Russians and 317 Ukrainians issued with work or student permits, while 302 Russians and 80 Ukrainians were granted permanent residence in New Zealand (Department of Labour, 2006).

Accordingly, the 2006 Census showed over 4,800 people self-identified as Russians (Statistics New Zealand, 2008). The more detailed information on the birthplace provided the numbers for those who stated to have been born in Russia $(4,578)$ and the Ukraine (1,152), showing more than three-fold increase in their numbers during the last decade (from 1,449 and 408 respectively). At the same time, there were 7,893 people who noted speaking the Russian language, classified into ethnicity categories as follows: 7,269 fell into a sub-group ‘European’; 259 - into a sub-group ‘Asian’; 
231 - 'New Zealander’; 159 - 'Middle Eastern/Latin American/African’, with smaller numbers in some other sub-groups (Statistics New Zealand, 2008).

Due to the small numbers of different ethnicities that can be grouped together under the label of Russian speakers (Russians, Russian Jews, Ukrainian, Byelorussians and others), there are no detailed data related to other aspects of this group, such as employment status, place of residence in New Zealand, and others. As illustrated earlier, the Census data cannot be fully reliable either, as Russian-speaking immigrants can classify themselves as ‘Europeans' or 'Jews' or 'New Zealanders', especially after having gained New Zealand citizenship as in latter case.

For that reason, the numbers of Russian-speaking immigrants in Wellington can only present a very inaccurate estimate. There is only anecdotal evidence, for example, that there are about 700 families of Russian-speaking immigrants living in Wellington, not counting singles. But even this figure is confusing, as it is impossible to estimate an average number in a Russian family - it may vary between two spouses and three generations, therefore, any estimate is unable to indicate how many Russian speakers reside in Wellington.

\section{Method}

\section{Design and Data Collection}

The principles of the qualitative paradigm for both the data collection and the data analysis were used in the study (Seale, Gobo, Gubrium \& Silverman, 2004). It was enlightened by the general principles of ethnographic enquiry (Gergen, 1990; Merriam, 2002), adapted in order to suit the requirements of collecting data among immigrants who were co-nationals with the first author (Colic-Peisker, 2004; Elias, 2005).

The data were collected via in-depth interviews with 23 participants (12 men and 11 women) recruited by word-of-mouth and snowballing among the Russian-speaking community in Wellington, New Zealand. Their ages ranged from around 20 to 60 years. They were all 'recent' migrants (i.e., they arrived in New Zealand within last 10 years), were mostly tertiary educated and many of them spoke English quite well. 
The interviews were conducted either at the participants' homes or at the university research facility, and lasted from around 30 to 90 minutes.

Seven questions, with additional prompts within each question, were derived for an interview schedule. The examples of the questions were: 'How do you feel in New Zealand society? How do you position yourself within New Zealand society? Has immigration made a difference to how you see yourself as a person?'

The interviews were originally conducted and recorded in Russian, then transcribed and translated into English by the first author. The English transcripts of the interviews were verified with two research assistants: a native New Zealand English speaker (for the purpose of capturing the New Zealand specifics of the English language); and a bilingual Russian-English interpreter (for the inter-rater reliability in matching the English version of the data with the Russian one).

Conducting interviews in Russian was possible due to the bilingualism of the first author, a Russian immigrant herself. The advantage of studying behaviour in one's own culture allows a researcher to have 'de facto an insider's cultural perspective' (Greenfield, 2000, p. 233, emphasis in the original). Apart from the ability to understand and capture the meanings articulated by the participants in their native language, similar life experience (for example, the same migration history) provides such a researcher with the possibility of gaining trust and forming unique rapport with the participants (Colic-Peisker, 2004).

However, writing the results of the research in English and presenting the main implications to the wider population, as well as the whole research community, ultimately creates an outsider position for the researcher. Greenfield (2000) defines such researchers in the following way: 'more important to the methodology of cultural and cross-cultural psychology is the role of the culturally marginal person; these are people who have had important socializing experiences in more than one culture' (p. 233). 


\section{Data Analysis}

The data were analysed using the rationale of the thematic analysis (Braun \& Clarke, 2006) and engaging the positioning theory as an analytical framework (Harré \& Van Langenhove, 1999). According to Braun and Clarke (2006), thematic analysis aims at identifying and interpreting dominant and important patterns (themes) within data. This method was preferred to other qualitative techniques, due to the translated nature of the data.

The theoretical position behind the analysis of the translated data may be grounded in the idea of a double interpretation: 'The participants are trying to make sense of their world; the researcher is trying to make sense of the participants trying to make sense of their world' (Smith \& Osborn, 2003, p. 51). Therefore, the process of translating the data becomes a part of the analysis, since, in order to translate the ideas, concepts and meanings constructed by the participants during the interviewing process, they already have to be re-interpreted within a different linguistic system.

The advantage of using thematic analysis is that it allowed for the conceptual interpretation of broader themes and patterns within the data, rather than coding and interpreting the particular words and phrases. At the same time, the discursive approach was also used to analyse small extracts of the data in cases when the participants referred to some issues in English, or where the direct translation from Russian into English was possible. Words and phrases given by the participants in English are presented in the text in italics. Words presented in CAPITAL letters indicate the additional emphasis placed on them by the speaker. For the purpose of identifying the extracts from the interviews, each participant has been given a number, which is preceded by a $W$ for women and an $M$ for men. Each quote is followed by a brief demographic note on the participant, including age, gender, marital status, and occupation/employment status.

\section{Analysis and Discussion}

As a result of the analysis of the data, several themes were identified on the basis of the most common and important issues for the majority of the participants. These themes were: Identity Loss; Inferior Labels; Normalizing Process; Grounding in Location; Re-claiming Ownership; and New Breed of People. Five out of these six 
themes were articulated by the participants with equal importance, however, for the purpose of this paper, the last theme - New Breed of People - is examined in more detail as the most relevant to the issue of the impact of global processes on immigration.

\section{Identity Loss}

One of the most common and salient themes across nearly all interviews was the theme of Identity Loss, based on the participants' accounts about the feelings and thoughts they experienced as a result of immigration to New Zealand. The issue of identity loss reaches its extreme manifestation in the case of refugees and asylum seekers who sometimes are stripped of any aspects of social identity and are reduced to 'their physical selves' (Colic-Peisker \& Walker, 2003, p. 341). Though the main condition for such feelings of loss is usually the very nature of a refugee status and what is linked to it, these traumatic experiences are not limited to refugees or asylum seekers. Many voluntary immigrants may also experience similar sense of the loss of their identity if the new socio-cultural environment fails to reconfirm the aspects of their identity constructed on the basis of their previous professional, cultural and social experience.

For example, many participants in this study talked about feeling as 'strangers', 'aliens', or as 'a nobody', as positioned by the host population. Though many of them arrived in New Zealand after having been granted a permanent residence status on the basis of their qualifications and previous work experience, very soon they found out that those aspects of their professional identity were not recognized by their new society of residence as valid or needed:

M9: On arriving here, the first thing that was done... say, the reaction of this society, well, probably, of any society... the first thing is to show you that you are a nobody!.. You are a stranger, you are a nobody! Well, that was the first impression, which I felt when I tried to find a job. With all my previous... university degree... it was straight away clear that all your... qualifications go into the rubbish bin. [49, male, married with two children, computer specialist]. 
The previous research on the economic implications of immigration of professionals and their families from the former Soviet Union to the USA identified an absolute loss of human capital for the majority of the sample (Gang \& Stuart, 2000). Consistent with the past research, some participants in this study talked about the mismatch between the way they expected their identity to be recognised by the New Zealand society and the actual response of most New Zealanders. Others, even when they did not expect their professional identity to be validated by the new socio-cultural environment, still reported feelings of identity loss in other social aspects, often referring to the image of a second rank of people: 'W20: I feel all the time like some sort of unclaimed, second rank, right..? and... absolutely not needed by anyone here and, maybe, even uninteresting...' [42, female, married with one child, unemployed psychologist].

As a result, the participants' whole sense of identity as valuable members of society was often undermined, or sometimes became virtually redundant, 'null and void'.

\section{Inferior Labels}

This void in immigrants' identity was filled in by various identity constructions of 'difference' between most immigrant groups and the host population. This articulation of difference often manifested in inferior and negative labels reflected upon by the participants, such as 'alien', 'inadequate', 'unequal' and others. These discourses were grouped under the common theme Inferior Labels. As Matheson (2005) suggests, labels are used as a discursive device in order to divide people into separate social categories. 'The act of labelling a person (or group or thing) defines how members of the society can understand and judge any action done by that person and allows them to generalize about them’ (Matheson, 2005, p. 24). Through labels, a person or a group of people can be discursively constructed as different, or inferior to the rest of population, which may signify social marginalization for this person or group (Matheson, 2005).

In the case of immigrants, many negative labels assigned to them by the host population add to the construction of an overall inferior identity of an immigrant, contrasted to the identity of a local. Being new to the society, immigrants are often seen as lacking profound knowledge of local customs and traditions, including 
fluency in English or the 'right' accent. This 'lack' of, or 'gap' in, particular local knowledge is sometimes labelled as a 'deficit' and may work for the construction of a 'handicap' identity, creating a stigma of an intellectual disability. For example, one of the participants commented:

W10: But overall it was funny. I mean, people... if I don’t speak English... (they would treat me)... as mental, as brain damaged... they would take me somewhere by my hand and lead me... [35, female, married with one child, unemployed accountant].

The 'abnormal' or 'deviant' construction of cultural identity may be used by the host society to claim power to dominate and discriminate the 'inferior' groups of population, including immigrants (Cottle, 2000; Yurdakul \& Bodemann, 2006). Language fluency was one of the most salient issues voiced by the participants in this study, as important as the issue of employment and professional identity. The fact that most of them speak with a strong 'alien' accent, make grammatical and semantic mistakes, often do not understand jokes or local references, leads them to feel disadvantaged as the society around them makes a conclusion about their intellectual inadequacy as equal to partial illiteracy. Their ‘uncultured' accent becomes a 'stigma symbol' (Rapoport et al., 2002), identifying them as outsiders.

Colic-Peisker (2002) states that in such multi-ethnic countries as Australia, there exists a cultural hierarchy of accents functioning as social markers. Some accents that identify speakers as American or French nationals may be considered prestigious, while others become a symbol of otherness, as they 'may associate the speaker with places commonly perceived as ‘backward' and ‘uncivilized' (p. 153). Thus, even between different migrant groups there can be a symbolic divide into 'cultural insiders' and 'cultural outsiders'. Colic-Peisker (2002) notes that for Europeanlooking Croatian immigrants in Australia, coming from a non-English speaking background 'may be a source of discrimination in employment just as skin colour or religion may be for other migrant groups' (p. 162). Consistent with her research, many participants in this study described the incidents of discrimination towards them which was based on their accent: 
M15: Yes, I do have an accent, I will never get rid of it but I know that people understand me... But... many people have... for example, a lady would insist... that she cannot understand me... Only for the sake of emphasizing, "You have an accent! I don’t want to understand you! I don’t want to listen to you!” To such an extent: “Give me somebody who speaks English...” [44, male, married with one child, bank employee].

Overall, many participants in this study mentioned that the host society saw them as inferior and unequal. Quite often they tried to explain various negative labels assigned to them by the fact of belonging to the group of immigrants. The mere membership in this category was seen by the participants as an inevitable inferior label, the reason for their exclusion from the wider society and the grounds for prejudice:

(Q: So, at this present moment... how do you feel here, who do you feel you are here?) W10: Well, certainly, an immigrant, I really feel like an immigrant here... probably, because, for example... in conversation... I cannot position myself as an equal. [35, female, married with one child, unemployed accountant].

The participants' understanding of their inferior status was expressed through the common perception (from their perspective) of an overall negative attitude towards immigrants as a particular amorphous group in New Zealand, regardless of ethnicity or culture. Similarly, the data from the comparison study on attitudes towards immigrants collected in 2003 and 2006 (Gendall, Spoonley \& Trlin, 2007) showed an increase of racist remarks about immigrants within that period, with evidence of a 'hardening' of the unspoken requirement for immigrants to adopt New Zealand customs and traditions as part of a 'common culture'. The strongest negative position towards immigrants was held by Maori respondents, in comparison to non-Maori (Gendall et al., 2007). There were no data from the participants in this study on Maori versus non-Maori attitudes towards them, but their accounts were consistent with the previous research on racist and exclusionary practices among New Zealanders which formed the basis for discrimination and inequality. 
This acceptance of an unequal status prescribed for them by the society signifies the powerless position of immigrants and their inability to claim agency in the process of constructing their own identity. For some participants in this study, though, the acceptance of inferior identity constructions was reported as only the beginning of the process of re-construction of their previous identity and the creation of a new one.

\section{Normalizing Process}

As another way of dealing with the sense of identity loss and the inferior label of an immigrant, or an alien, many of the participants used the strategy of normalization of their negative experiences. As suggested by Rapoport et al. (2002), to engage in a normalizing process would entail negotiating unfavourable identity constructions by transferring the blame for this onto self. This strategy may be used by immigrants in order to re-claim their sense of identity as they refuse to accept the power of society to dictate its rules of construction. The inferior identity constructions may be re-framed by immigrants as 'normal', on the basis of the taken-for-granted difference between immigrants and the rest of population. These constructions in the participants' responses were grouped under the theme Normalizing Process. For example, one of the participants ascribed her feeling of alienation as her own fault:

W11: Of course, I feel some slight alienation... Well, and sometimes it seems to me, though, of course, nobody says anything to my face... but maybe, it’s my lack of confidence... Sometimes it seems to me that I am still ALIEN to them... But it is probably normal, I do not stress out due to this... [43, female, married with one child, scientific researcher].

The notions of 'alien' and 'normal' function as markers for the process through which the participants try to make sense of the ways their identity is constructed by their immediate socio-cultural environment. They accept the status of 'aliens' assigned to them by the wider society through re-articulating this 'alien' identity as being 'normal', or, in other words, as expected by others. This normalizing strategy is used by immigrants to fight the powerless position assigned to them by the host society, by the way of accepting the negative labels and re-framing them into the 'normal' ones. Engaging this strategy signals their intention to exercise agency in relation to their identity. 


\section{Grounding in Location}

At the same time, many immigrants choose to fight various negative identity constructions imposed on them by the host society, refusing to accept them in any manner. Another way agency may be claimed by immigrants is illustrated by the theme Grounding in Location. This theme was constructed on the basis of the participants' responses to the question often posed to them, 'Where do you come from?'

Through this question, even before receiving an answer, the inferior identity of an immigrant - as an alien, a stranger, a foreigner, not belonging to the local community - is constructed. This question is seen by many participants as humiliating and apriori rejecting their loyalty towards the society they now live in. They feel that it immediately constructs their identity as different from 'normal', at the same time introducing the reference frame and the 'rules' of belonging to this society. The mere act of posing such a question entails the construction of a symbolic border - 'We are from here, while you are obviously not. So, where are you from?'

Colic-Peisker, in her research with Croatian immigrants in Australia (2004), reflects on a similar response of migrants to this question, 'In Australia... I became a person who speaks 'with an accent' and was repeatedly asked where I had come from... Many migrants... resent being asked, "Where do you come from?” They feel that the question defines them as outsiders’ (p. 82).

Several participants preferred to answer this question in an unconventional way, trying to draw the attention to the fact that they had been living in New Zealand as valid residents or citizens for quite a large amount of time. They do this by avoiding naming their country of origin and by giving instead their current address in New Zealand in a form of the Wellington suburb they reside at present:

Interviewer: How do you introduce yourself to New Zealanders? M8: Well, they usually ask... start with... a stupid question, "Where are you from?” To this question I always reply, “From Miramar”. Here, they start thinking, feel lost for a moment and then the most intelligent say, “That's great 
but I am asking you where your accent comes from.” I say, "Well, my accent is from Moscow”. [52, male, married with one child, taxi-driver].

One of the participants tries to ridicule the whole idea of investigating cultural origins through constructing his own label in response to this question. His answer rejects the idea of identification through ethnic origin and positions his identity firmly within the geographical location which omits any ethnic or cultural markers:

M9: Well, a question comes... "Where do you come from? Where are you from?” Well... I have prepared a standard answer, “I am from Miramar. I am a

Miramartian”. [49, male, married with two children, computer specialist].

This metaphor constructs an extreme case of an 'alien' identity (as a 'true extraterrestrial' - from Mars) and illustrates how inappropriate the label of cultural 'aliens' can be. By rejecting the 'alien' identity through grounding their current position within New Zealand territorial space, the participants tried to claim the status of locals and emphasize their loyalty to their new place of residence. Through identifying their origin by local places, the participants sought to re-position themselves as insiders, demanding the inclusion and acceptance by the locals on an equal basis. Therefore, their grounding in geographical locations emphasised their claim for agency and co-ownership of the same socio-cultural resources with the host population.

\section{Re-claiming Ownership}

To be able to claim their part in ownership of socio-cultural resources in the society, immigrants face the necessity of adjusting and adapting to the existing systems of meanings around them. The theme Re-claiming Ownership illustrates the participants' accounts of their engagement in creating their new sense of identity. The notion of ‘cultural learning' (Ward, Bochner, \& Furnham, 2001), or gaining an insider knowledge of a new cultural environment, was emphasized by many participants as a necessary condition for re-constructing their identity of full members of society:

W7: I want to become part of this country, I want to learn about it, to get to know its people, its history, and its culture... I hope that after having lived here, 
maybe, for five more years, at least, and not simply having lived but having learned more... about New Zealand, and having got to know New Zealand people, maybe, I would like very much... to feel myself as a Kiwi. [48, female, married with two children, nanny].

Several participants used the metaphors of material construction in articulating the changes they experienced in their sense of self. In this process, some of them admit the power of the immediate environment in shaping their identity, while others stress their own agency:

W10: It's interesting to look at oneself as if from outside... how all these sharp corners flatten... with time. It's like being sculpted...[35, female, married with one child, unemployed accountant].

M9: I started moulding myself into this society. Precisely, I meant gaining this... local tertiary education... And after I got it... ultimately... what many local young people cannot achieve; after I got, eventually, this job... which again many locals cannot get either... then I realised that I am ultimately... not a complete fool. [49, male, married with two children, computer specialist].

As a result of successful re-claiming of the ownership over their identity and the ability to re-construct the desired sense of self, many participants experienced the feeling of personal growth, articulated by them through various constructions, such as notions of 'self-worth', 'self-esteem', 'self-respect' and others:

W12: So, it's like that: you have already proven yourself, you have achieved something, and you already think of yourself, “Ah! I can do this”...So, you sort of start to realise what you are worth, and what not... and how you can handle overall all these... difficult situations in life, quite hard ones... [36, female, married with one child, midwife].

One of the illustrations of the participants' successful cultural learning and their ability to use local socio-cultural resources in re-constructing their identity may be the 
fact that many of them use English words (such as 'self-esteem') as discursive constructions of self, in parallel to Russian linguistic devices:

M9: My self-esteem has risen dramatically... whether they like me or not... if they employ me, ready to pay and... even rejected some local applicants in order to employ exclusively me... it means in general... That was some sort of grounds for self-esteem... in terms of professional criteria, so to say, selfevaluation, right? [49, male, married with two children, computer specialist].

While undergoing this process of re-construction and creation of new identity, many participants attempt to find the explanations for these considerable transformations to their sense of self. They search for meanings behind these processes and try to make sense of their relationship with others and the wider society. The issue of belonging to a particular group of society, be that a community of Russian-speaking immigrants, or the wider group of immigrants to New Zealand, or the whole New Zealand society, is investigated by many participants from different angles. Their accounts are presented by an overarching theme New Breed of People which illustrates their attempts to make sense of their identity as different from others'.

\section{New Breed of People}

Madison (2006) in his study on experiences of voluntary migrants suggests the concept of existential migration - the type of migration people engage in when they see it as a necessary condition for their life, or the mere nature of their existence. He argues that among different types of migrants there are some '...voluntary migrants [who] are seeking greater possibilities for self-actualising, exploring foreign cultures in order to assess their own identity, and ultimately grappling with issues of home and belonging in the world generally' (p. 238). Madison's concept of existential migration is echoed in the accounts of the participants in this study for whom the act of immigration signifies more than a necessary adaptation and integration into a new socio-cultural environment.

Several participants in this study suggested that immigrants are overall different from both the host population, and the majority of the population in their country of origin. The theme New Breed of People was based on their accounts about the nature of their 
immigration experiences and the need to find some explanations for their move to another country. These participants constructed themselves, and similar to them other immigrants, first of all, as unique, in terms of the personal qualities they possessed even before immigrating. These qualities were seen by them as an utter necessity for survival and the future success in new environments.

For example, one participant talks about the higher motivation and resilience common to the families of migrants in contrast to others:

W20: And quite often immigrants are more ambitious... And the children of immigrants who are brought up in families... who are... struggling with... the life conditions... Really, the first two-three years... when immigrants arrive here... it is virtually a BATTLE, and... children are taught by their families... to fall and stand up again..! and go further... and they are taught also to achieve things. So, the motivation in immigrant families... is much higher, than... in native families... [42, female, married with one child, unemployed psychologist].

Another participant emphasizes the idea that immigrants are above average in their abilities and are active, compared with the rest of population in any country constructed as 'sitting still':

M23: I am not average. The fact that I managed to get here... and ANY immigrant is not an average person... And a person who breaks away... is not average anymore. In Russia, I am not average. I am above average, and by the way, much above average. And here I am much above average because I am that person who wants to take off somewhere... If you are average, you sit still and don't stick out... Any immigrant is more active... by default. Those people who move [away] from their place, as a rule, are more active, more mobile. A person who is running is more active than the one who is sitting... [47, male, married with three children, secondary teacher].

On the basis of such personal qualities, existing prior to immigration, some participants constructed a symbolic representation of a person who differs from the 
rest of society: a challenger, an adventurer, a conqueror. For example, the notion of possessing an adventurous character is articulated by one of the participants as the impossibility of staying in one place:

W6: ...my friends were telling me, back in Russia, "Well, you probably will adapt anywhere and make friends even in Antarctica... We even wouldn’t go anywhere... what for? ... to leave everything and move to God knows where, so to say...” There are just people who... can't sit still in one place... who seek adventures... [28, female, single, IT specialist].

She further develops the image of an adventurer using the metaphor of 'conquering', as an antithesis to 'sitting still'. The concept of migration is framed by her as a desire 'to conquer' other countries, where new challenges make life 'interesting', while a ‘conquered' challenge becomes 'boring' and unfulfilling:

W6: I simply came here to have a look... Well, now it's already boring for me. I mean there is lots of stuff here you can do but... Though I had three jobs back home... I did not want anything... everything sort of stopped... so, it was already necessary... to make some movements... Here now too... it's time to move already... to conquer Australia, for example, or somewhere else. It's interesting to go THERE... even just to have a look. [28, female, single, IT specialist].

Another participant points out that the phenomenon of taking on challenges is not restricted only to Russian immigrants; he gives an example of a New Zealander who is guided by the same motives to migrate as other immigrants:

M23: I know a Kiwi who... works in Norway, having learned to speak Norwegian... He is active. Here you have the example of an immigrant too. He went there, learned Norwegian. And now he works for some big company... Here, you would think, such a challenge! I mean, he also immigrated, the same stuff... But he feels great, he is active, it's interesting for him, he is learning something new. [47, male, married with three children, secondary teacher]. 
Together with emphasizing the necessary qualities which put these immigrants into a group of people different from the rest of society, and constructing the symbolic representation for this new category, many participants try to find explanations for this difference and articulate their ideas about the underlying processes behind this new identity. One of the participants suggests certain ambivalence, in terms of not having a strong sense of belonging to any of the societies he has been living in. For him, the ties which most people find strong enough to hold them to a particular place or culture, or generate some nostalgia when they have to leave those, are not so important and would not stop him from going to other places:

M9: ...maybe, after having got all [this]... it is worth to go and work in another country... No specific... sentimental values... have emerged, so that they would hold me to this country. What distinguishes migrants from non-migrants is that they have a weaker link... to sentimental values... A part of me... is left back home. The same thing is possible here... there is already some Kiwi part in me, which ALSO exists and which probably later on I will miss too. Nevertheless, none of these parts... is strong enough... to stop me from going for something better...[49, male, married with two children, computer specialist].

In explanation of this new identity, some participants use biological, or genetic, discourse. One of the participants, in his attempt to make sense of the difference this type of immigrants presents in comparison to others, uses a genetic framework to articulate his justification for this difference, as well as a metaphor of mathematical dissimilarity:

M23: It is a type of a person, it must be some sort of a genetic make-up, probably... let's say... You cannot compare me with an average Kiwi because... we are like different units, mathematically. I am more... onto it... more bold... more trying to... infiltrate everywhere... find out everything... But he doesn't need this, what for? ... He was told what to do and that's it...[47, male, married with three children, secondary teacher].

The nature of such a difference is assigned by one of the participants to some condition from birth, which makes him feel an outsider in any society in the world, 
including his place of origin. He interlaces the English words outsider and identity into Russian while articulating his difference from others. By this, he uses the resources of both socio-cultural milieux in constructing his identity, while at the same time, claiming no strong membership with either of them:

M9: I felt as an outside observer even in that society from which I have arrived. I did not identify myself with that society... The same way, I do not identify myself with this society either. So, in some sense, I feel like an outsider. Which doesn't prevent me, in general, from adapting to this society... Many immigrants cannot adapt to the full. In my case, it's also part of me, myself, my identity... that I am not likely to identify myself with anything. (Interviewer: Is this feeling of an outsider present all the time in your life?) Well, it's a part of me, frankly speaking... Or, so to say, I was born like that. [49, male, married with two children, computer specialist].

Again, the apriori qualities, articulated here as a condition from birth, are used as a construction of a category which can be re-framed as the theme New Breed of People. This theme illustrates that these participants resort to a biological explanation, constructing themselves (as similar others) as some kind of 'species', or group, biologically or genetically different from other people.

\section{Conclusion}

Not all of the participants felt the same way about their immigration experience. Through coming to terms with the feeling of loss of their previous identity and the imposed inferior labels of an immigrant constructed for them by others, some participants in this study aimed at re-constructing their identity by either placing it within the community of other immigrants, normalized by them as a valid part of New Zealand society, or by grounding it locally and claiming the agency and membership among New Zealanders.

At the same time, there were participants who constructed themselves differently, as those destined to become migrants, due to their personal qualities or some other factors in their life. Madison's (2006) concept of existential migration resonated with these participants' feelings and experiences, as they tried to make sense of their 
difference through the biological (or genetic) explanation for this type or sub-group of immigrants, re-framed by a metaphor of a New Breed of People. The notion of an immigrant positioned as 'an outsider' or 'an alien' by the majority of population was seen by these participants to be equally valid for immigrants across different nations. In this regard, they saw more common features with immigrants from other countries than with people from their culture of origin or the host population.

This notion of a different type of people not rooted in any particular culture or community but eager to embrace many of them simultaneously and equally may be grounded in a concept of cosmopolitan thinking, dating back to Diogenes' notion of 'a citizen of the world' (Cronin, 2006). Cosmopolitanism may be seen as a kind of world-view and as a socio-cultural condition and it entails the notion of a complex polyidentity, based on the idea of multiple subjects having 'a plurality of different loyalties, a multiplicity of different ways in which they can be described or defined' (Cronin, 2006, p. 9).

In contrast to a single or hybrid identity, rooted within (a) particular geographic and cultural space(s), cosmopolitan identity may be seen as constituted within the notion of global space, inclusive of multiple identities of equal value. While communitarianism, often promoted in the form of multiculturalism and cultural pluralism, prioritizes some primary identity rooted in a particular community of belonging, cosmopolitan identity is based on multiple affiliation, with an emphasis on 'the ability to make one's way into other cultures and to actively engage with those living in or through different cultures, languages or milieux’ (Cronin, 2006, p. 10).

This very ability, constructed by some participants in this study as an indispensable quality or as a feature from birth, is characteristic of these new actors in global space, the agents of cosmopolitan thinking. The new, global, ways of thinking about the world and interactions between cultures are constructed by these new agents, who by doing this, at the same time increase the availability of the necessary resources for their own identity construction.

In view of the projections for the future, current trends indicate that the processes of both globalization and mass migration will only intensify, with an even more 
increasing speed and scale. In the conjunction with these processes, the new ways of identity construction can also be projected as becoming more complex, diverse and encompassing, as well as producing novel identities, thus, bringing all of us even more closer to the common identity of 'a citizen of the world'. The role of global civil society will only be strengthened, with an increasing emphasis on universal rights of cosmopolitan citizens - the new agents of new, global, consciousness.

\section{Acknowledgements}

The authors would like to gratefully acknowledge Dr Deborah Laurs and Polina Kobeleva for their help with the verification of the English version of the transcripts.

\section{Bibliography}

Braun, V., \& Clarke, V. 2006, 'Using thematic analysis in psychology', Qualitative Research in Psychology, 3, pp. 77-101.

Burr, V. 1995, An Introduction to Social Constructionism, Routledge, London.

Castles, S., \& Miller, M. J. 2003, The Age of Migration ( $3^{\text {rd }}$ ed), Guilford Press, New York.

Chandler, D. 2005, Constructing Global Society: Morality and Power in International Relations, Palgrave Macmillan, New York.

Colic-Peisker, V. 2002, 'Croatians in Western Australia: migration, language and class', Journal of Sociology, vol. 38 no. 2, pp. 149-166.

Colic-Peisker, V. 2004, 'Doing ethnography in “One’s own ethnic community”'. In L. Hume \& J. Mulcock (eds), Anthropologists in the field: Cases in Participant Observation, Columbia University Press, New York pp. 82-94.

Colic-Peisker, V., \& Walker, I. 2003, 'Human capital, acculturation and social identity: Bosnian refugees in Australia', Journal of Community and Applied Social Psychology, vol. 13, no. 5, pp. 337-360.

Cottle, S. 2000, Ethnic Minorities and the Media: Changing Cultural Boundaries. Open University Press, Philadelphia.

Cronin, M. 2006, Translation and identity, Routledge, London.

Department of Labour. 2006, Migration trends 2005/2006. Retrieved 21 January 2008. from www.dol.govt.nz.

Elias, N. 2005, 'Living in Germany, longing for Israel: The elderly Jewish immigrants from the former Soviet Union in Germany', East European Jewish Affairs, vol. 35, pp. 167-187.

Gang, I. N., \& Stuart, R. C. 2000, 'Does background matter? The transmission of human capital from a planned to a market economy', International Migration Review, vol. 34, no.2, pp. 511-521.

Gendall, P., Spoonley, P., \& Trlin, A. 2007, The attitudes of New Zealanders to immigrants and immigration: 2003 and 2006 compared. New Settlers Programme, Massey University, Palmerston North.

Gergen, K. J. 1990, 'Social understanding and the inscription of self' in J. W. Stigler, R. A. Shweder \& G. Herdt (eds.), Cultural Psychology: Essays on 
Comparative Human Development, Cambridge University Press, Cambridge: pp. 569-606.

Gergen, K. J. 1991, The Saturated Self: Dilemmas in Identity in Contemporary Life. Basic Books, New York.

Greenfield, P. M. 2000, 'Three approaches to the psychology of culture: Where do they come from? Where can they go?' Asian Journal of Social Psychology, vol. 3, no. 3, pp. 223-240.

Harré, R., \& Van Langenhove, L. 1999, Positioning theory: Moral contexts of intentional action, Blackwell Publishers, Oxford.

Liu, J. H., \& Hilton, D. J. 2005, 'How the past weights on the present: Social representations of history and their role in identity politics', The British Journal of Social Psychology, vol. 44, no. 4, pp. 537-557.

Liu, J. H., McCreanor, T., McIntosh, T., \& Teaiwa, T. 2005, New Zealand Identities: Departures and Destinations, Victoria University Press, Wellington.

Keane, J. 2003, Global Civil Society? Cambridge University Press, Cambridge.

Kononenko, P. P., \& Holowinsky, I. Z. 2001, ,Educational reform and language issue in Ukraine' in N. K. Shimahara, I. Z. Holowinsky \& S. Tomlinson-Clarke (Eds.), Ethnicity, Race and Nationality in Education: A Global Perspective, Lawrence Erlbaum Associates, Mahwah, NJ, pp. 213-232.

Madison, G. 2006, ‘Existential migration', Existential Analysis, vol. 17, pp. 238-260.

Maydell-Stevens, E., Masgoret, A.-M., \& Ward, T. 2007, 'Problems in psychological and socio-cultural adaptation among Russian-speaking immigrants in New Zealand', Social Policy Journal of New Zealand, vol. 30, pp.178-198.

Markowitz, F. 2004, 'Talking about culture: Globalization, human rights and anthropology', Anthropological Theory, vol. 4, no. 3, pp. 329-352.

Matheson, D. 2005, Media Discourses: Analysing Media Texts, Open University Press, Maidenhead.

Merriam, S. B. 2002, 'Introduction to qualitative research', in S. B. Merriam (ed.), Qualitative Research in Practice: Examples for Discussion and Analysis, Jossey-Bass, San Francisco, pp. 3-17.

Nash, M., Wong, J., \& Trlin, A. 2006, 'Civil and social integration: A new field of social work practice with immigrants, refugees and asylum seekers', International Social Work, vol. 49, pp. 345-363.

Rapoport, T., Lomsky-Feder, E., \& Heider, A. 2002, 'Recollection and relocation in immigration: Russian-Jewish immigrants "normalize” their anti-Semitic experiences’, Symbolic Interaction, vol.25, pp. 175-198.

Resnik, J. 2006, 'Alternative identities in multicultural schools in Israel: emancipatory identity, mixed identity and transnational identity', British Journal of Sociology of Education, vol. 27, pp. 585-601.

Sampson, E. E. 1989, 'The challenge of social change for psychology: Globalization and psychology's theory of the person', American Psychologist, vol. 44, pp. 914-921.

Seale, C., Gobo, G., Gubrium, J.F., \& Silverman, D. 2004, Qualitative Research Practice, Sage, London.

Scholte, J. A. 2005, Globalization: A Critical Introduction. Palgrave Macmillan, New York.

Shaw, M. 2000, Theory of the Global State: Globality as Unfinished Revolution. Cambridge University Press San Francisco.

Smith, J. A., \& Osborn, M. 2003, 'Interpretative phenomenological analysis', in J. A. Smith (ed), Qualitative Psychology Sage, London, pp. 51-80. 
Statistics New Zealand. 2002, 2001 Census: National Summary. Retrieved April 13th 2004. from http://www.stats.govt.nz.

Statistics New Zealand. 2008, Longitudinal Immigration Survey: New Zealand (LisNZ) - Wave 1. Retrieved 19 May 2008. from http://www.stats.govt.nz.

Suarez-Orozco, M. M. 2005, 'Right moves? Immigration, globalization, utopia, and dystopia', in M. M. Suarez-Orozco, C. Suarez-Orozco \& D. B. Qin (eds), The New Immigration: An Interdisciplinary Reader, Brunner-Routledge, New York, pp. 3-20.

Vinokurov, A., Birman, D., \& Trickett, E. 2000, 'Psychological and acculturation correlates of work status among Soviet Jewish refugees in the United States', International Migration Review, vol. 34, no. 2, pp. 538-555.

Ward, C., Bochner, S., \& Furnham, A. 2001, The Psychology of Culture Shock (2nd ed), Routledge, Hove.

Yurdakul, G., \& Bodemann, Y. M. 2006, 'Introduction', in Y. M. Bodemann \& G. Yurdakul (eds), Migration, Citizenship, Ethnos Palgrave Macmillan, New York, pp. 1-12. 